IZA DP No. 5982

\title{
A Decade of Editing the European Economic Review
}

\author{
Zvi Eckstein \\ Esther Gal-Or \\ Thorvaldur Gylfason \\ Jürgen von Hagen \\ Gerard Pfann
}

September 2011 


\title{
A Decade of Editing the European Economic Review
}

\author{
Zvi Eckstein \\ Bank of Israel, Tel Aviv University, CEPR and IZA
}

Esther Gal-Or

University of Pittsburgh

\section{Thorvaldur Gylfason}

University of Iceland

Jürgen von Hagen

IIW, University of Bonn

Gerard Pfann

Maastricht University and IZA

\section{Discussion Paper No. 5982 \\ September 2011}

\author{
IZA \\ P.O. Box 7240 \\ 53072 Bonn \\ Germany \\ Phone: +49-228-3894-0 \\ Fax: +49-228-3894-180 \\ E-mail: iza@iza.org
}

\begin{abstract}
Any opinions expressed here are those of the author(s) and not those of IZA. Research published in this series may include views on policy, but the institute itself takes no institutional policy positions.

The Institute for the Study of Labor (IZA) in Bonn is a local and virtual international research center and a place of communication between science, politics and business. IZA is an independent nonprofit organization supported by Deutsche Post Foundation. The center is associated with the University of Bonn and offers a stimulating research environment through its international network, workshops and conferences, data service, project support, research visits and doctoral program. IZA engages in (i) original and internationally competitive research in all fields of labor economics, (ii) development of policy concepts, and (iii) dissemination of research results and concepts to the interested public.
\end{abstract}

IZA Discussion Papers often represent preliminary work and are circulated to encourage discussion. Citation of such a paper should account for its provisional character. A revised version may be available directly from the author. 
IZA Discussion Paper No. 5982

September 2011

\section{ABSTRACT}

\section{A Decade of Editing the European Economic Review*}

This story describes the circumstances that led to all five of us starting as editors at the same time, the unexpected things we have found, the unanticipated reactions we have encountered, how we worked as an editorial team, the central role of the editorial office manager, how we managed to work with five different publishers in ten years, the various initiatives we have developed to involve associate editors and referees, the early electronic editing system, and the creation of the essential database of potential referees. We will also describe the difficulties we have encountered in reaching one of our early goals to reduce the median time of first response to less than four months. Along the way, we will share a few anecdotes to illustrate the work of an academic journal editor.

JEL Classification: $\quad$ A11, A14

Keywords: journal, editing, economics

Corresponding author:

Gerard A. Pfann

Maastricht University

School of Business and Economics

6200 MD Maastricht

The Netherlands

E-mail: g.pfann@maastrichtuniversity.nl

\footnotetext{
${ }^{*}$ The authors blame one another for any shortcomings of the text.
} 
At the end of 2002 we were called upon to edit the European Economic Review (EER). We are a team of five editors who live in the US, Iceland, Germany, Israel, and Holland. We accepted articles from all over the world but mainly from European and American economists in roughly similar numbers. This is not really surprising as we all know that there isn't such a thing as European economics that is different from American economics. There are preferences, tendencies, and market phenomena that economists residing in different countries try to explain. The editing of a scientific journal is a ceaseless search for new and exciting ideas. This chapter tells the story of our expedition that started a decade ago. What unites us is the love for the scientific approach of economic discovery. What we have in common is the determination to help -- especially young -- economists to communicate their findings and share new ideas with other economists. A wonderful byproduct of our joint effort has been the close friendship we have developed over the decade of working together. We are grateful for having had the opportunity to assist in the dissemination of new ideas and methodologies to the research community. We hope that some of these ideas will help in overcoming the hard economic times the world is currently facing.

This story describes the circumstances that led to all five of us starting as editors at the same time, the unexpected things we have found, the unanticipated reactions we have encountered, how we worked as an editorial team, the central role of the editorial office manager, how we managed to work with five different publishers in ten years, the various initiatives we have developed to involve associate editors and referees, the early electronic editing system, and the creation of the essential database of potential referees. We will also describe the difficulties we have encountered in reaching one of our early goals to reduce the median time of first response to 
less than four months. Along the way, we will share a few anecdotes to illustrate the work of an academic journal editor.

\section{How it started}

In the summer of 2002 the entire former board of editors of the EER stepped down as the result of a concerted action of the European Economic Association (EEA) to cut all ties with the journal's publishing company Elsevier, apparently with the intention to ditch the EER. The dispute, in a nutshell, was about Elsevier's pricing policy, later transforming to a fight about the journal's authority, and eventually, its ownership. The EEA, founded in 1986, was granted the option to use the EER as the Association's signature journal. With the growing success of the EEA over the seventeen years of its existence, the association claimed ownership of the EER, a claim Elsevier denied. Mr. Joop Dirkmaat was the publisher at Elsevier responsible for the EER at the time. For Joop the separation was like a bad dream, as the EER was Elsevier's flagship journal for its continuously growing portfolio of economics journals. He contacted Mr. Gerard Pfann to gauge his interest in helping save the journal from demise. Joop knew Gerard from the time they had successfully co-founded the Journal of Empirical Finance in 1993. The situation was complicated by the fact that the EEA announced the founding of a new journal to compete with the EER. Gerard saw at least two reasons to accept Joop's request. First, the reputation of the EER was already well established prior to the founding of the Association, and in this respect, it had the first-mover advantage. Second, while competition for the EER in continental Europe was a new phenomenon, most economists would agree that such competition was healthy and likely to improve the performance of both journals. Moreover, Joop was determined to continue publishing the journal whatever the cost. Gerard had only one fundamental request, namely that the whole operation must be electronic, so that no more paper files and articles would need to be 
delivered by the postman. Elsevier had just purchased a program called Editorial Manager (EDGMR) for the development of electronic editing. Initially, the program was only available for the medical sciences, and its format at the time was not suitable for the completely different editorial culture in economics. Together, Joop and Gerard decided to adjust EDGMR to the demands of economics editing. They also agreed to establish an Editorial Office run by someone in Gerard's vicinity, someone who knew the mores of academic publishing, who was an excellent and respectful communicator, computer literate, and fluent in English. Finally, they identified the fields of expertise that needed to be covered by different editors. The expectation was that the market for academic articles would continue to grow for some years. While in 2002 the number of submissions received by the EER each year was around 350, the expectation was that the ongoing revolution in electronic publishing would lead to a substantial increase of this number to roughly 500-600 per year. Given this forecast, Joop and Gerard decided to recruit a total of 5-6 editors. Mr. Thorvaldur Gylfason (growth and development) and Mr. Jürgen von Hagen (money \& banking, international macro, international finance, exchange rates) were the first to join the editorial team, followed by Mrs. Esther Gal-Or (economic theory, industrial organization, experimental economics, behavioral economics), and Mr. Zvi Eckstein (macro economics, search models, education, immigration, history, empirical industrial organization). Gerard (labor, investment, finance, econometrics) assumed the role of Managing Editor.

In January 2003 the electronic EDMGR was up and running. This was mainly due to the immense effort of Mrs. Carina Furnée, the new Editorial Office Manager, and of Mr. Ruud Meesters from Elsevier who was responsible for EDMGR and its relationship with Elsevier. Together they adjusted and redesigned the entire electronic routing and communication systems of EDMGR to make it suitable for economics editing. The EER became the first journal in 
economics that was run entirely electronically. Being first implied though that we had to deal with quirks in the system that by today's standards of electronic systems seem a bit ridiculous. Take, for instance, the processing of submission fees. Over time an increasing number of submissions came with hand-written forms that contained wrong or unidentifiable credit card details. From time to time Carina received from Elsevier an envelope with large amounts of these forms. Even though the submissions were already in process, the envelopes came with the request to contact each of the corresponding authors personally so as to keep open the possibility of collecting the agreed fees. This meant a huge amount of rather unpleasant work on top of the Editorial Office's regular workload. Since the envelopes arrived with long delays a large number of the papers concerned had already been dealt with. Authors whose papers had been rejected had naturally very little incentive to pay the submission fees in spite of repeated calls and email messages.

\section{Boxes full of manuscripts and referee reports}

In the meantime, between the summer of 2002 and spring 2003, about half a dozen of cardboard boxes were dispatched to the Editorial Office. The boxes were filled with paper files and came from the former editors. Most of these boxes came from Paris, on behalf of Mr. Xavier Vives, EER's former Managing Editor. After a rather slow start, Xavier was truly cooperative in helping to solve the problem of the large number of manuscripts that were under consideration and urgently needed to be dealt with. In addition, the other former four editors sent 118 unfinished files separately to our office. Many long nights were spent to sort out the paper files, tie the loose ends, and correspond with authors who had been waiting patiently for updates on the status of their papers. 
We faced a back-log of papers so large that once a paper was accepted for publication, authors had to wait at least 18 months before seeing their papers in print. The first aim we set ourselves was to shorten this waiting time to six months. With the help of Elsevier that allowed a temporary increase of the number of pages from 1200 in 2002 to 2100 in 2005, 2006, and 2007, we achieved our first goal in 2009. In that same year a new page layout was introduced for the EER with a larger page surface, so that each page contains 25 percent more information than in the previous layout (Figure 1).

\section{[INSERT FIGURE 1 ABOUT HERE]}

\section{The first meetings of the editorial board in 2003}

The first strategic discussions took place during the 2003 ASSA Meetings in Washington DC. We discussed the fields of expertise covered by the people who had expressed their willingness to join the EER as Associate Editors, and the lacunae. It was agreed that every editor would find ten AEs in non-overlapping specialized fields. This would translate to a group of about fifty AEs covering a wide range of fields. The hope was that this group would gain access to a very large network of expert reviewers. We concluded that it would be important to schedule another meeting of the new editors to continue formulating the strategic direction of journal. The first Editorial Meeting took place in Maastricht on Friday, April $11^{\text {th }}, 2003$. In addition to the five new editors, Joop and the new editorial office manager, Carina, were also in attendance.

At first we thought that two editorial meetings per year would be necessary only in the beginning, as we set the new strategic direction for the journal. Our plan was to shift to one annual meeting after a couple of years. It turned out, however, that this was not to be the case. Throughout our 
ten-year period as editors we continued to meet twice yearly: in the Spring and Fall. The advantages of meeting that often were numerous. We found that sharing information about difficulties we encountered with the new electronic system, with grievances from authors, and with the ongoing organizational changes at Elsevier helped us run the journal more smoothly. There were frequent changes of staff at Elsevier's publishing department throughout our tenure as editors. During this period we have worked with five different publishers with gradually shrinking freedom to navigate the direction of the journal. Joop was succeeded by Mr. David Clark in 2005. In 2007 the extra hierarchical level of "Senior Vice-President (SVP)" was introduced at Elsevier. David Clark moved to such an SVP position in another discipline, and Mrs. Valerie Teng took over the EER with Mrs. Diane Cogan becoming her superior officer. In 2009 Diane Cogan left Elsevier and her responsibility with respect to the EER was taken over by Mr. Patrick Jackson as SVP. When Valerie Teng left Elsevier shortly thereafter, she was temporarily replaced by Mrs. Jenny Henzen, and subsequently, in the summer of 2010 Mrs. Daniela Georgescu became the next publisher responsible for the EER, while Jackson as SVP remained in control in the background. Organizational memory is not long, and it took much effort on our part to stick to the general direction we had forged for the journal. Thankfully, there are some indications that we were successful. The changes that took place in 2002 did not lead to a reduction in the number of submissions. In fact, the number of submissions increased by almost a quarter in comparison with 2002 (Figure 2). Moreover, in spite of the larger number of extra papers published between 2005 and 2007, Thomson's ISI Impact Factor did not suffer either (Figure 3).

[INSERT FIGURE 2 ABOUT HERE]

[INSERT FIGURE 3 ABOUT HERE] 


\section{Incentives for Associate Editors}

Fifty Associate Editors is a large number of people. With half of the submissions distributed uniformly among Associate Editors, an Associate Editor received an average 3.5 papers in 2003 and 6 papers in 2010. With the increase in the number of submissions, the demand on an Associate Editor's time almost doubled over the past decade. Sending out an invitation to an Associate Editor to handle papers is asking a favor, and we do not like to ask our friends and colleagues too many favors. We realized that we had to offer the Associate Editors something in return for their efforts on behalf of the journal. This issue of the role of Associate Editors was discussed at every Editorial Board meeting from the outset. Paying Associate Editors - or reviewers for that matter - for their time spent on a paper was not an option, simply because it was considered too costly, both financially and administratively. So we had to come up with alternative tokens of appreciation. Here is a list of what we had to offer:

\section{Invitations to Dinners at the Annual ASSA and EEA Meetings}

All Associate Editors received invitations to dinners during the annual meetings of the European Economic Association Meetings in August and the Allied Social Sciences Association Meetings in January. This way we sought to create two opportunities per year for social interaction between the Editors and Associate Editors. Two especially memorable dinners were given at the Everest in the Chicago Stock Exchange and the Puerta de Atocha in Madrid's central railway station. Over time the number of Associate Editors attending the meetings or the time available during the meetings diminished. In 2007 David Clark asked us to reconsider the dinners, and we agreed to discontinue this activity given the low attendance rate of Associate Editors. Associate 
Editors have continued to receive invitations from Elsevier to join the Annual Cocktail Party organized during the ASSA meetings since 2009.

\section{Organizing Workshops on Original and New Topics in Economics}

Joop and Gerard agreed that Elsevier allocate some resources for the organization of one workshop per year on a new topic in economics. The objective was that an Associate Editor would initiate the idea for the workshop and organize it in conjunction with one of the five Editors. Each workshop was held for at most two conference days and included 10 to 15 papers. Two expert reviewers were also invited to each workshop with the intent that they help the Associate Editors to select four or five papers to be considered for publication in a Special Section - called a "Symposium" - of the European Economic Review. This Special Section was guaranteed fast publication in a future issue of the EER, and the authors of the selected papers had the opportunity to also publish their contributions to the workshop in a volume of conference proceedings. Elsevier agreed to publish the proceedings in its prestigious Green Series under the title of "Contributions to Economic Analysis.” The Associate Editor who initiated the idea for the workshop together with one of the editors formed the editorial team for the Special Section and the proceedings. We decided to take turns in organizing these conferences. In 2005, for instance, we included a Special Section on The Economics of Time Use joint with Associate Editor Daniel Hamermesh (see Figure 4), and in 2010 Tom Gresik helped us edit a Special Section on Multinational Taxation and Tax Competition.

\section{[INSERT FIGURE 4 ABOUT HERE]}




\section{Acting As a Reviewer}

We extended to the Associate Editors the option to act as reviewers for papers assigned to them and, therefore, be eligible for the reward offered to reviewers for timely completion of their reports. The reward comprised of a voucher worth $€ 125$ allowing reviewers to purchase any Elsevier product. The vouchers were used mostly to buy selected copies from Elsevier's "Handbooks in Economics" series. In 2009 Elsevier handed over the entire Handbook operation to an independent subsidiary within its own company, and we were informed that the review voucher could no longer be used to buy Handbooks. Since then vouchers were mostly used as waivers for submission fees to the EER. Associate Editors were exempted from paying submission fees anyhow, and thus, we lost this valuable incentive for Associate Editors.

\section{Access to Science Direct and SciVerse SCOPUS}

Editors and Associate Editors received free access to Science Direct. In 2010 the complete Handbooks in Economics Series became available from Science Direct and Associate Editors had, therefore, free electronic access to articles published in these Handbooks. In addition, in 2010 a new platform, SciVerse SCOPUS, became available that is comparable to the Web of Science and Google Scholar. It included a search engine useful for finding referees and viewing articles related to submitted papers. Valerie and Gerard agreed that Editors and Associate Editors would obtain free access to this new platform as well because of its likely usefulness in the review process. For Associate Editors who were affiliated with organizations that had institutional subscriptions to these products the value of this free access was rather limited. 


\section{European Economic Review Talented Economists Clinic}

The dwindling amenities available to Associate Editors encouraged us to seek new alternatives. In 2008 we started a new initiative that we named the European Economic Review Talented Economists Clinic. Our objective was to use the submission fees paid to the journal for the benefit of young academic economists, a segment of the community that had been of prime interest to us from the start. The idea was for each editor to identify one of the best performing Associate Editors in a given year, and invite him (her) to select two young and promising economists in his (her) field of expertise. The selected economists were invited to present their work at the yearly EERTEC meeting to be attended also by the five Associate Editors and all five editors. The meeting created the opportunity for the young academic economists to receive comments from the different editors, and be introduced to the publishing culture at top-tier economics journals. The EERTEC meeting was also an excellent vehicle for invitees to network with other talented peers and to establish first roots for future possible collaborations. We did not try to sway the authors to submit their work to the EER. We advised them, in fact, that gaining exposure by publishing at the very top outlets might actually serve their professional careers better. However, we suggested that if at some point in the future they did decide to submit their work to the EER they would be exempted from paying the submission fee. The first three meetings were organized in collaboration with the European University Institute in Florence in cooperation with Mr. Luigi Guiso, one of our Associate Editors. The fourth meeting took place at IZA in Bonn. All expenses for the authors and Associate Editors were covered using submission fees.

[INSERT FIGURE 5: Picture of First EERTEC Meeting in Florence, May 2008] 


\section{Special Initiatives and Commissioned Papers}

In addition to the Special Sections that were initiated by Associate Editors we decided to publish sections to commemorate special occasions or to cover new fields of research in economics. For instance, in 2005 Zvi took the initiative to add a series of papers from the conference in honor of Mr. Dale Mortensen's $60^{\text {th }}$ birthday. Together Zvi and Dale edited a Special Section on Labor Search that we published in 2006. In 2008 we were pleased to commemorate the fiftieth anniversary of the Phillips curve in conjunction with the Kiel Institute for the World Economy. In early 2011, we could publish, in two symposiums, papers from workshops organized in the summer and fall of 2010 dealing with different aspects of the international financial crisis that started in 2008. This gave the EER a head-start among economics journals engaging in the academic debate over the causes of the crisis and the policies dealing with it. We decided not to publish one of the Special Sections early on, for which we received nine papers from the organizer of the workshop, because eight of the papers of the workshop were coauthored by the this organizer. Finally, in 2012 we plan to publish our last Special Section titled "Green Buildings, Economics and Public Policy”. In addition to Special Sections, we commissioned survey articles on "hot" topics in economics. They included "The Returns to Schooling in Structural Dynamic Models” by Christian Belzil in 2007, “Search in Cities” by Yves Zenou in 2009, “Field Experiments in Economics” by Steve Levitt and John List in 2009, and “Myopia, Redistribution and Pensions” by Helmuth Cremer and Pierre Pestieau in 2011.

\section{Why we could not get the time to first response down to 4 months}

Long delays between the submission of a paper and the time when an author receives an editorial decision are a problem in today's culture of economics journals. From the start, we tried to work against this problem with various measures. One of the first we took was to introduce turbo 
rejects, i.e., rejections of papers without giving them to reviewers. The idea was to return to the authors immediately papers that we as editors thought had very small chances of making it through the reviewing process successfully. In this way, we would save authors unnecessary waiting times and economize on the valuable time of our potential reviewers. Authors have generally been quite happy with this idea which nowadays seems to become standard for economics journals.

Yet, if there is one thing we regret deeply it is our failure to achieve the objective of four months as the median response time between a complete submission and first decision on a paper. We set out this objective early in our term with regard to papers that were not turbo (desk) rejected. There were multiple reasons for our inability to achieve this goal. Some had to do with the shortcomings of Elsevier's electronic system, others with the increase in the number of submissions we experienced over time, and still others relate to the slowness of the review process itself.

Elsevier's electronic system (first EDMGR and subsequently EES) did not include a feature that allowed each editor to monitor the elapsed time in the various stages of the review process of papers assigned to him (her). In particular, the efficiency measure pertaining to the duration of the period to first response did not separate turbo rejected papers from other submissions, and did not provide individualized measures for the different editors. With turbo-rejected papers included, our efficiency measure appeared much more favorable than it really was. Moreover, since we did not obtain individualized performance measures we could not share information about processes and techniques that were helpful in hastening the review process. In spite of 
repeated requests, Elsevier did not include the above mentioned two features in its electronic system.

With regard to the number of submissions, the increase from around 350 to 550 per year with a steady number of Associate Editors implied that we had to assume the role of AE's on an increasingly bigger number of manuscripts. This meant identifying referees ourselves for a bigger share of submitted papers. Finally, in spite of incentives offered for timely reports, we encountered great difficulties with some reviewers. It was not uncommon for the editorial office to find it necessary to send second and third reminders to reviewers who promised reports but never delivered. There was, for instance, a referee who upon being reminded for the fourth time that his promised report was long overdue, responded by saying that we could not imagine the disruptions created by the recent earthquake close to his hometown and, by the way, whether we would care to have a look at his three recent papers, attached, in case we might find them interesting.

\section{Conclusion}

The decade we have spent together as editors has been a great experience. While we were not able to accomplish all of our goals, we hope that we were successful in contributing to the advancement and dissemination of knowledge in economics. We derived great pleasure from interacting with authors, referees and Associate Editors from all over the world. Among them was the author who thanked us for having accepted his paper for publication against the rather hostile advice of one of the referees and who had then been awarded a prestigious prize for the published paper. We got a kick out of that. Or another author of a turbo rejected paper who contacted us one year after the rejection to thank us for the quick review process and 
recommendation for the alternative outlet for publication. His paper had just been accepted in this alternative outlet. But all good things must come to an end. It is time for us now to step down and allow a new team of editors to bring new ideas and approaches to running the EER. We wish them all the best and good luck in advancing the reputation of the journal. 
Figure 1:

Number of Pages Published by the EER

Between 2003 and 2010

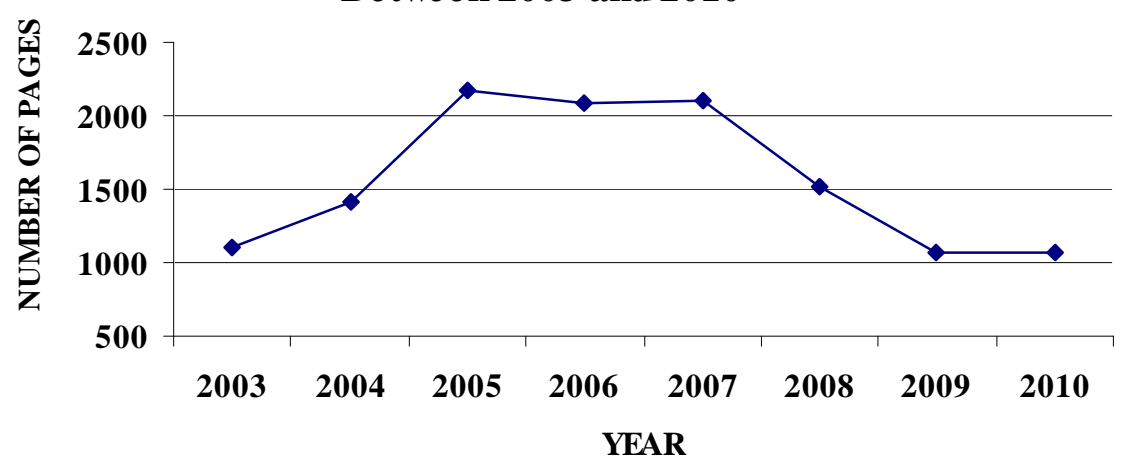


Figure 2:

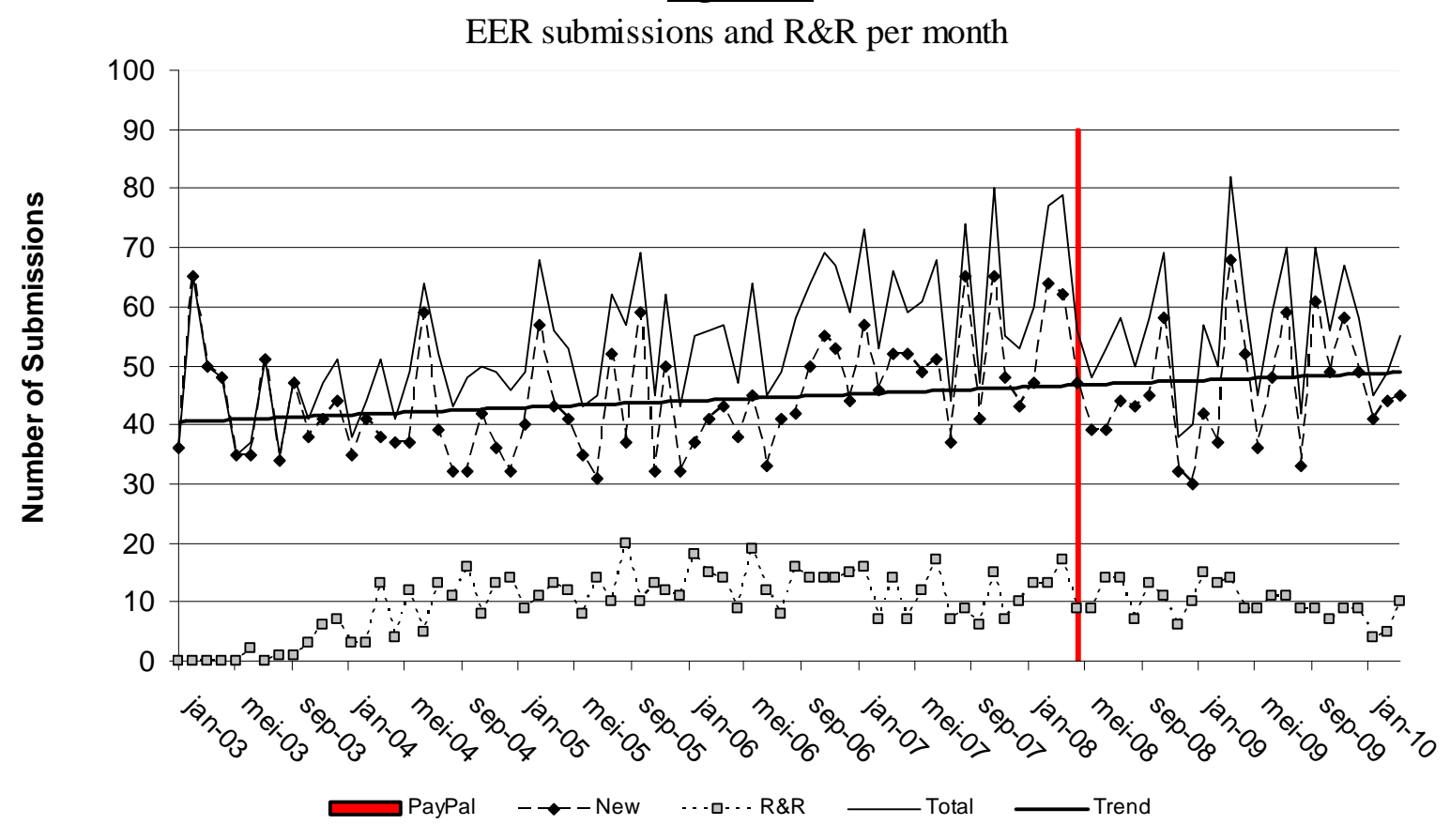


Figure 3:

EER -- Thomson ISI Impact Factor

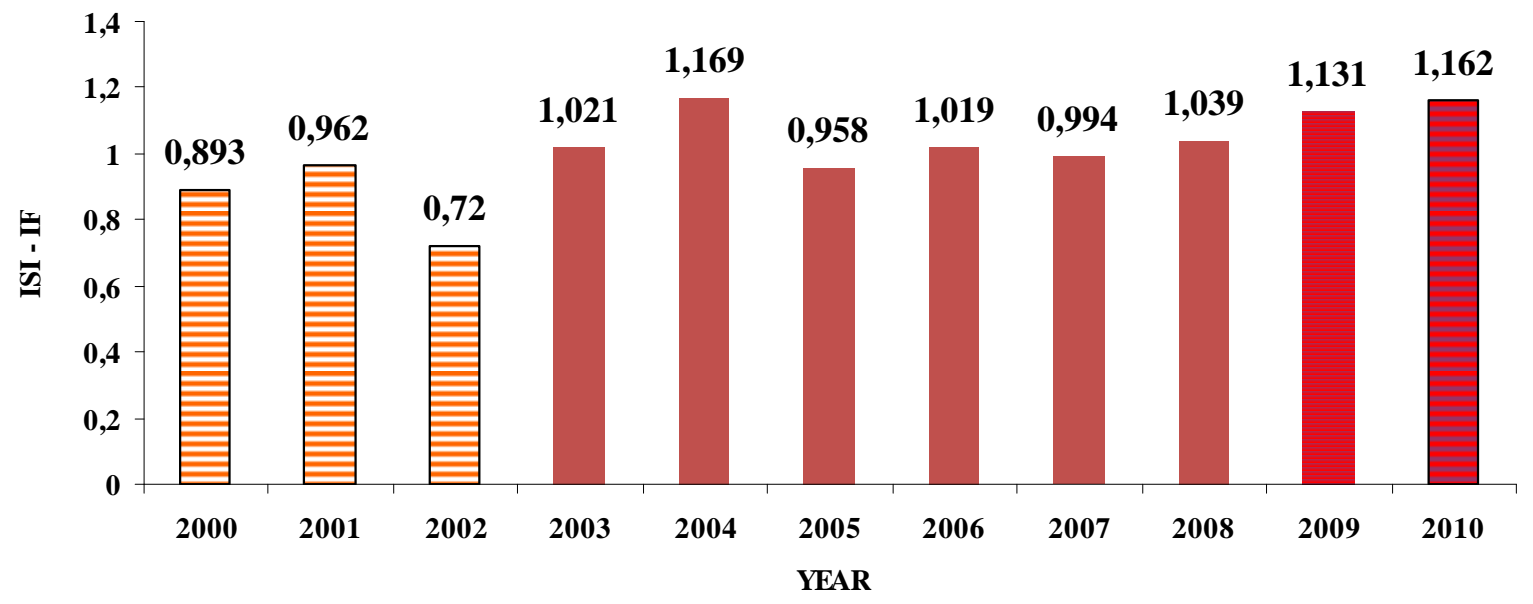




\section{Figure 4}

The Economics of Time Use

Contributions of Economic Analysis Vol.271 (2005)

Edited by Daniel S. Hamermesh and Gerard A. Pfann

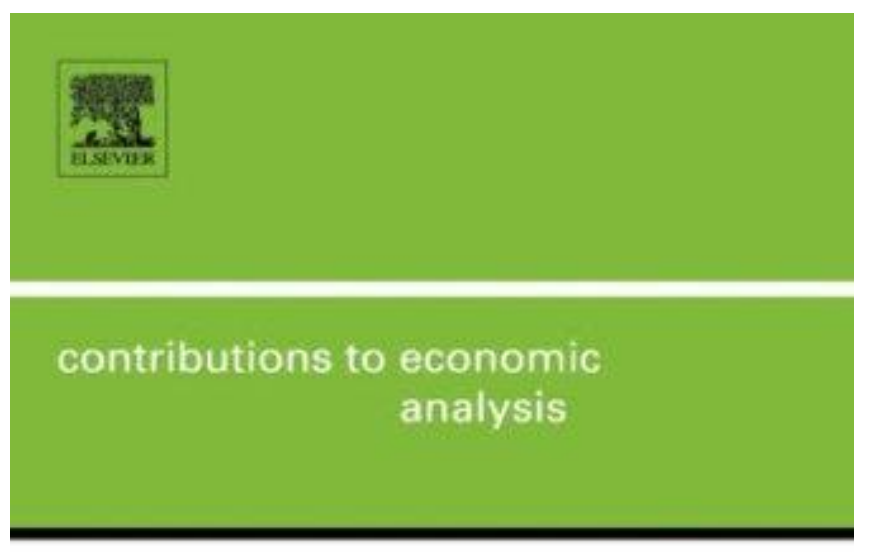

Daniel S. Hamermesh and Gerard A. PHann

Editors

The Economics of Time Use 


\section{Figure 5}

The First European Economic Review Talented Economists Clinic The European University Institute, Fiesole, Florence, 28-30 May 2008

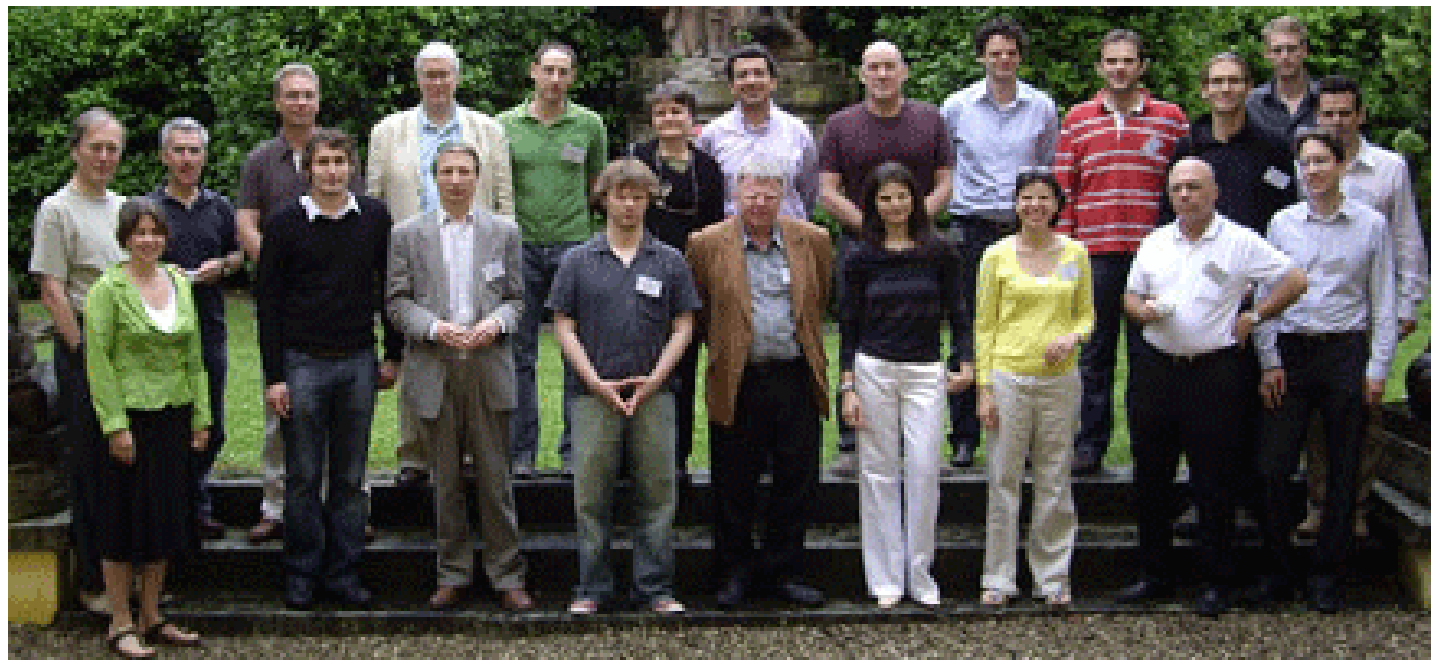

